\title{
Age-Dependent Influence of Hypoxia on Methionine-Enkephalin Concentration within Rabbit Brainstem Nuclei
}

\author{
J. L. GingRAS-LEATHERMAN, M. C. McNAMARA, AND E. E. LAWSON \\ Department of Pediatrics, Duke University Medical Center, Durham, North Carolina 27710 [J.L.G.-L.] and \\ University of North Carolina, Chapel Hill, North Carolina 27514 [M.C.M., E.E.L.]
}

\begin{abstract}
We examined the effect of hypoxia $\left(\mathrm{FIO}_{2}=\right.$ 0.10) on methionine-enkephalin concentrations in brainstem nuclei involved in the integration of cardiopulmonary control in 3- and 21-day-old rabbits. Rabbit pups were confined in environmental chambers for $6 \mathrm{~h}$ and exposed to one of four conditions. Control, $21 \% \mathrm{O}_{2}$ for $6 \mathrm{~h}$; intermittent hypoxia, 12 cycles of $20 \mathrm{~min} 21 \% \mathrm{O}_{2}$ followed by $10 \mathrm{~min}$ of $10 \% \mathrm{O}_{2}$; acute hypoxia, $4 \mathrm{~h}$ of $21 \% \mathrm{O}_{2}$ followed by $2 \mathrm{~h}$ of $10 \% \mathrm{O}_{2}$; recovery, $2 \mathrm{~h}$ of $10 \% \mathrm{O}_{2}$ followed by 4 h of $21 \% \mathrm{O}_{2}$. Methionine-enkephalin was measured by radioimmunoassay in the nucleus tractus solitarius, nucleus ambiguus, nucleus parabrachialismedialis, and nucleus reticulogigantocellularis. In 3-day-old rabbits, exposure to $10 \% \mathrm{O}_{2}$ did not affect methionine-enkephalin concentrations in any brainstem nuclei studied. In contrast, 21-dayold pups demonstrated a decrease in methionine-enkephalin concentration in three of the four nuclei studied when exposed to intermittent hypoxia, as well as an apparent ability to recover from an acute hypoxic exposure $(p<$ $0.05)$. These data support an age-, nucleus-, and stimulusspecific effect of hypoxia on methionine-enkephalin concentration within specific brainstem nuclei and suggest a possible mechanism for the newborn's increased cardiopulmonary instability under hypoxia. (Pediatr Res 20: 655657, 1986)
\end{abstract}

\section{Abbreviations}

ME, methionine-enkephalin

[ME], methionine-enkephalin concentration

ME has been implicated in modulation of a number of physiologic functions particularly nocioception and cardiovascular control $(1,2)$. Recently, its role in respiratory control has been suggested by both direct and indirect studies under basal conditions as well as under conditions of hypoxia and asphyxia (3-5). Indeed, ME may play a particularly important role in respiratory modulation of the fetus and newborn (6-8). This concept is supported by studies showing that naloxone, an opiate antagonist, decreases the duration of primary apnea in neonatal rabbits (9), reverses neonatal depression caused by fetal asphyxia (10),

Received December 13, 1985; accepted March 5, 1986.

Address for correspondence and reprints J. L. Gingras-Leatherman, M.D., Duke University Medical Center, Box 3967, Durham, NC 27710

This work was supported by Grants HD 00.475 and HD 19117 from the United Cerebral Palsy and the National Institute of Health. J.L.G.-L. was supported by a fellowship award from the Institute of Pediatric Services of the Johnson and Johnson Company and is currently an Edward L. Trudeau Scholar of the American Lung Association. and reverses the hypoxic respiratory depressant effects in neonatal but not older animals (11). ME receptors are found in high concentration within brainstem areas involved in cardiopulmonary control $(12,13)$, and, more specifically, studies from our laboratory have shown ME levels to be higher in young versus old rabbit brainstem nuclei involved in integration of cardiopulmonary control (14).

Hypoxia produces alterations in the concentration of classical neurotransmitters in the brains of adult and neonatal animals (15-18). However, little is known about the effects of hypoxia on levels of the neuropeptide ME. To determine whether hypoxia affects brainstem levels of the inhibitory opiate transmitter ME, we measured $[\mathrm{ME}]$ within specific brainstem nuclei in 3- and 21day-old animals after exposure to hypoxia. This study was undertaken in an effort to assess the central biochemical events that may influence the newborn's response to hypoxia. Our specific hypotheses were: 1) various hypoxic insults alter the central ME selectively within specific brainstem nuclei and 2) these alterations are age dependent.

\section{METHODS}

Three- and 21-day-old New Zealand/California rabbits were obtained from a local breeder on the morning of the experiments. The rabbits were confined for $6 \mathrm{~h}$ in water-jacketed environmental chambers. During this period they were exposed to one of four experimental conditions: 1) the control group breathed $21 \%$ oxygen in nitrogen for the duration of the study $(6 \mathrm{~h}) ; 2)$ the intermittent group were subjected to $20 \mathrm{~min}$ of $21 \%$ oxygen followed by $10 \mathrm{~min}$ of $10 \%$ oxygen for a total of twelve cycles; 3 ) the acute group initially breathed $21 \%$ oxygen for $4 \mathrm{~h}$ followed by $2 \mathrm{~h}$ of $10 \%$ oxygen; 4 ) the recovery group breathed $10 \%$ oxygen for $2 \mathrm{~h}$ and then breathed $21 \%$ oxygen for the remaining $4 \mathrm{~h}$. Chamber temperature was maintained between $36-37^{\circ} \mathrm{C}$ and the gas was warmed and humidified. Gas flow was adjusted to maintain the rebreathed $\mathrm{CO}_{2}$ below $0.2 \%$ measured by an infrared carbon dioxide analyzer (Beckman LB-2).

After $6 \mathrm{~h}$ of exposure, the animals were sacrificed either by rapid decapitation or cervical dislocation. To control for possible diurnal variation, all animals were killed between the hours of 4 and 5 PM. Following sacrifice, the brains were removed rapidly, sectioned into forebrain and brainstem regions, frozen, and stored at $-70^{\circ} \mathrm{C}$. Using landmarks previously described (14) the following nuclei were removed by a modification of the micropunch technique of Palkovits (19-21): nucleus tractus solitarius, nucleus ambiguus, nucleus parabrachialis-medialis, and nucleus reticulogigantocellularis. Two pellets of tissue were removed from each nucleus and (depending on age) tissue pellets from one ( 21 day old) and three ( 3 day old) animals were pooled. Total $n$ for each condition was 6 . The tissues were sonicated in $2 \mathrm{~N}$ acetic acid, lyophilized and stored at $-70^{\circ} \mathrm{C}$. ME was 
measured by radioimmunoassay (14) and protein was measured by the method of Lowry et al. (22). Data are reported as ng ME/ $\mathrm{mg}$ protein. Overall effects were shown by analysis of variance and subsequent analyses were done using the Wilcoxon signedranked test. Significance is reported at $p<0.05$.

\section{RESULTS}

[ME], expressed as $\mathrm{ng} / \mathrm{mg}$ protein $\pm \mathrm{SE}$ are shown in Figure 1. In control animals, $M E$ levels are highest in the nucleus ambiguus and nucleus tractus solitarius of the 3-day-old animals and the nucleus tractus solitarius of the 21-day-old animals and the lowest in the nucleus parabrachialis-medialis of both 3-and 21-day-old control rabbits. This rank order persists under hypoxia.

In the 3-day-old rabbits, analysis of variance demonstrated that there were no differences among the four study groups in [ME] of any given nuclei (Fig. 1, solid bars).

In the 21-day-old animals, significant differences in [ME] were found among the four study groups in all brainstem nuclei. Analysis demonstrated that in each of these nuclei at least one experimental condition was significantly different from control. The most consistent changes were observed in the intermittent group (Fig. 1, speckled bars). Exposure to $6 \mathrm{~h}$ of intermittent hypoxia resulted in decreased [ME] when compared to the control levels in three of the four nuclei studied. The changes in the acute and recovery groups were variable and occurred in only one (recovery) or two (acute) nuclei. When the ME values were transformed to percentage change from their control values, a specific relationship between the acute and recovery groups was observed. ME values within all nuclei of the recovery groups were closer to control values than those of the acute groups (Fig. 2 ). Although these differences between acute and recovery values do not represent changes occurring in the same animal, these data nonetheless support an apparent ability of the 21-day-old

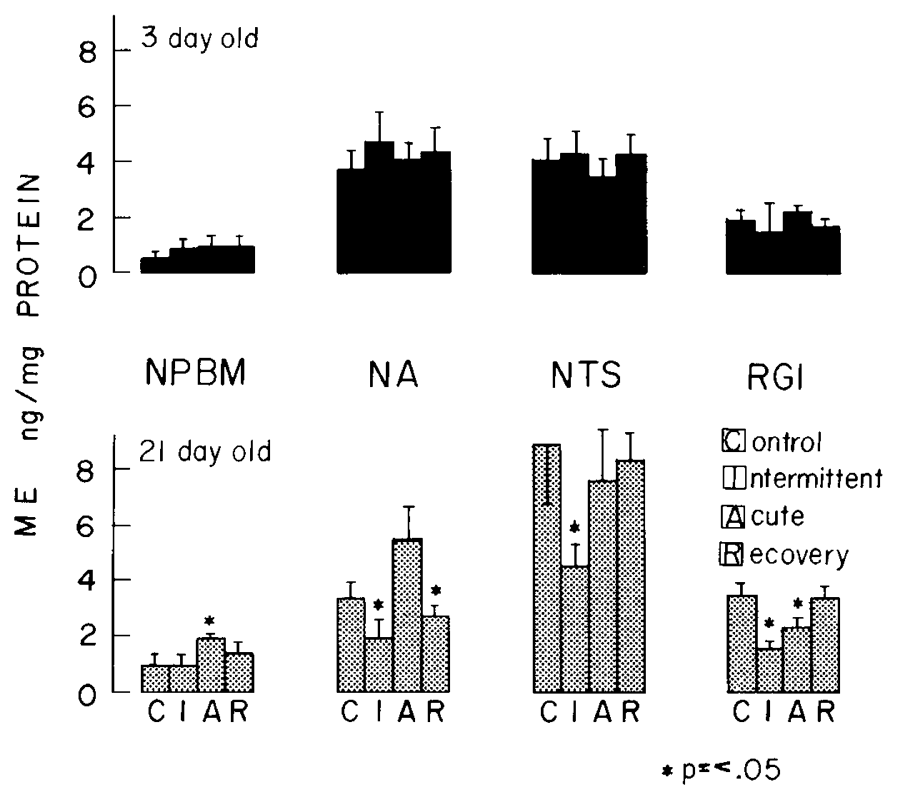

Fig. 1. $[\mathrm{ME}]$ in $\mathrm{ng} / \mathrm{mg}$ protein $\pm \mathrm{SEM}$ in 3-day-old (solid bars) and 21-day-old (speckled bars) rabbits under various hypoxia conditions. Control $(C)$ animals breathed $21 \% \mathrm{O}_{2}$ for $6 \mathrm{~h}$; intermittent $(I)$ animals breathed $21 \% \mathrm{O}_{2}$ for $20 \mathrm{~min}$ followed by $10 \mathrm{~min}$ of $10 \% \mathrm{O}_{2}$; acute $(A)$ animals breathed $21 \% \mathrm{O}_{2}$ for $4 \mathrm{~h}$ followed by $2 \mathrm{~h}$ of $10 \% \mathrm{O}_{2}$; recovery $(R)$ animals breathed $2 \mathrm{~h}$ of $10 \% \mathrm{O}_{2}$ followed by $4 \mathrm{~h}$ of $21 \% \mathrm{O}_{2}$. Animals were sacrificed at 6 h. Bar graphs represent the four conditions for each nucleus: $N P B M$, nucleus parabrachialismedialis; $N A$, nucleus ambiguus; $N T S$, nucleus tractus solitarius; $R G I$, nucleus reticulogigantocellularis. $* p<0.05$.

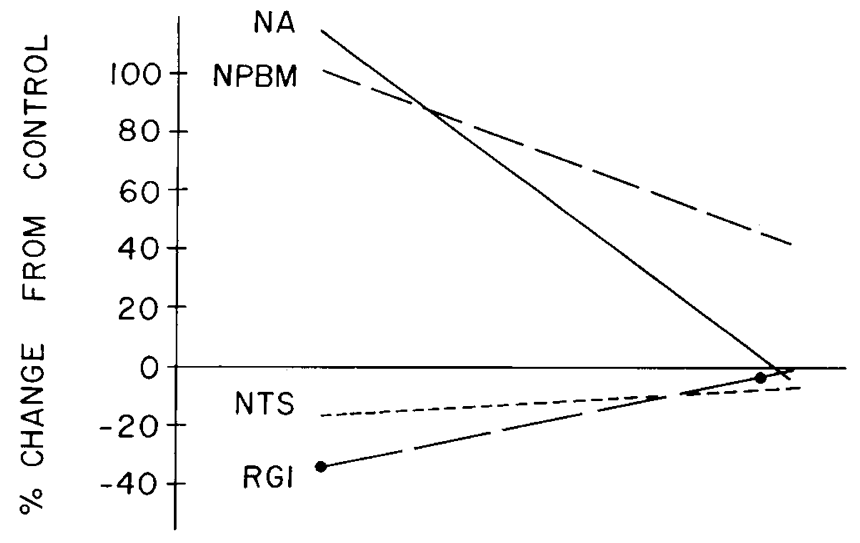

ACUTE

RECOVERY

Fig. 2. $[\mathrm{ME}]$ as percentage change from control in 21 -day-old animals after exposure to acute hypoxia (animals breathed $4 \mathrm{~h}$ of $21 \% \mathrm{O}_{2}$ followed by $2 \mathrm{~h}$ of $10 \% \mathrm{O}_{2}$ prior to sacrifice) and recovery (animals breathed $10 \%$ $\mathrm{O}_{2}$ for $2 \mathrm{~h}$ followed by $21 \% \mathrm{O}_{2}$ for $4 \mathrm{~h}$ prior to sacrifice) in the $N A$, nucleus ambiguus; $N P B M$, nucleus parabrachialismedialis; $N T S$, nucleus tractus solitarius; $R G I$, nucleus reticulogigantocellularis.

animals to recover from an acute hypoxia exposure. This occurred whether the initial response to acute hypoxia represented a decrease or increase in [ME].

\section{DISCUSSION}

Our results demonstrate a developmental pattern in [ME] response to hypoxia in certain brainstem nuclei. Exposure to 6 $\mathrm{h}$ of intermittent hypoxia decreased [ME] in the 21- but not 3day-old animals and recovery was possible in these animals. These results differ from those of Arregui et al. (23) who report an increase in immunoreactive $\mathrm{ME}$ in forebrain areas after exposure of 28-day-old rats to chronic hypoxia (3 wk of $10 \%$ $\mathrm{O}_{2}$ ). This difference may reflect age or species difference or, more likely, relates to the duration, extent, and nature of the hypoxic exposure. In addition, different brain regions may have variable responses to hypoxia.

That [ME] did not show any significant change under hypoxia in the 3-day-old animals tends to support the observation of Long and Lawson (24) that ME may not act as the primary neurotransmitter in the newborn's response to hypoxia, but do not exclude the view that ME has a modulatory role. In fact, ME has known functions as a neuromodulator $(25,26)$ and has recently been shown to coexist and modulate the release of other classical transmitters such as serotonin and norepinephrine (27, 28). The age-dependent changes in [ME] we observed may reflect an alteration in the balance of critical neurotransmitters within important relay nuclei within the central nervous system.

We have recently reported (29) that intermittent hypoxia causes an age-dependent decrease in serotonin concentration in other brainstem nuclei (locus coeruleus, dorsal raphe, substantia nigra) of 3-day-old animals while increasing concentrations of serotonin in 21-day-old animals. These findings, taken together with the present findings of age and stimulus specific changes in [ME], suggest developmentally related times during which the homeostatic balance between various transmitter systems may be disrupted by exogenous stimuli. In 3-day-old animals, the decrease in serotonin concentration without a concomitant change in ME disrupts this balance, thus, predisposing young animals to increased physiologic instability. Furthermore, in the 21-day-old animals, acute hypoxia caused variable and nucleus specific changes. These changes in ME levels showed a tendency to return to control levels with recovery suggesting an age-related maturation in the ability to regulate neurotransmitter content. 
In addition to changes in [ME], other factors affect the function of a transmitter such as receptor density and affinity, and transmitter release, synthesis, and degradation. Each of these factors may be altered under various hypoxic conditions thereby influencing the physiologic response for the [ME]. Zamir et al. (30) have recently demonstrated that central processing of endogenous opiates vary depending on specific brain regions. Similarly, it is likely that stressors such as hypoxia affect the metabolism of endogenous opiates in an age- and nucleus-specific manner as is suggested by our data.

In summary, this study supports the growing concept that the neonatal response to environmental stressors are mediated through mechanisms that are nucleus, stimulus, and age dependent. These responses place the newborn at particular risk for centrally induced cardiopulmonary instability.

Acknowledgments. The authors thank Dr. A. Joseph D'Ercole for his critical review of this manuscript and Ms. Folu Moses for her secretarial assistance.

\section{REFERENCES}

1. Olson GA, Olsen RD, Kastin AJ 1983 Endogenous opiates: 1982. Peptides 4:563-576

2. Olson GA, Olsen RD, Kastin AJ, Coy DH 1982 Endogenous opiates: 1981 Peptides 3:1039-1072

3. Haddad GG, Gandhi MR, Hochwald GM, Lai TL 1983 Enkephalin-induced changes in ventilation and ventilatory pattern in adult dogs. $\mathbf{J}$ Appl Physiol $55: 1311-1320$

4. Hedner T, Hedner J, Bergman B, Lundberg D 1981 Transient apnea after enkephalin analogue in the preterm rabbit. Biol Neonate 39:290-294

5. Lawson EE, Waldrop TG, Eldridge FL 1979 Naloxone enhances respiratory output in cats. J Appl Physiol 47:1105-1111

6. Jansen AH, Chernick V 1983 Development of respiratory control. Physiol Rev $63: 437-483$

7. Lagercrantz H 1984 Classical and "new" neurotransmitters during development-some examples from control of respiration. J Dev Physiol 6:195-205

8. Trippenback T 1983 Effects of drugs on the respiratory control system in the perinatal period and during postnatal development. Pharm Ther 20:307340

9. Chernick V, Madansky D, Lawson EE 1980 Naloxone decreases the duration of primary apnea with neonatal asphyxia. Pediatr Res 14:357-359

10. Chernick V, Craig K 1982 Naloxone reverses neonatal depression caused by fetal asphyxia. Science 216:1252-1253
11. Grunstein M, Grunstein J 1982 Maturational effect of enkephalin on respiratory control in newborn rabbits. J Appl Physiol 53:1063-1070

12. Khachaturian H, Lewis ME, Watson SJ 1983 Enkephalin systems in diencephalon and brainstem of the rat. J Comp Neurol 220:310-320

13. Maley B, Elde R 1982 Immunohistochemical localization of putative neurotransmitters within the feline nucleus tractus solitarius. Neuroscience 7:2469-2490

14. Gingras-Leatherman JL, McNamara CM, Lawson EE, Hong HS 1985 Development of methionine-enkephalin in microdissected rabbit brain nuclei. Brain Res 336:73-80

15. Brown RM, Kehr W, Carlsson A 1975 Functional and biochemical aspects of catecholamine metabolism in brain under hypoxia. Brain Res 85:491-509

16. Davis J, Carlsson A, MacMillan V, Siesjo B 1973 Brain tryptophan hydroxylase depends on arterial oxygen tension. Science 182:72-74

17. Hedner T, Lunborg P, Engel J 1977 Effect of hypoxia on monoamine syntheses in brains of developing rats. Biol Neonate 32:229-236

18. Jilek $\mathrm{L} 1970$ The reaction and adaptation of the CNS to stagnant hypoxia and anoxia during ontogeny. In: Himwich W (ed) Developmental Neurobiology. Charles C Thomas, New York, pp 331-369

19. McNamara MC, Lawson EE 1984 Turnover and synthesis of biogenic amines in discrete brainstem nuclei of the rabbit. Brain Res 299:259-264

20. Palkovits M, Brownstein MJ 1983 Microdissection of brain areas by the punch technique. In: Cuello AC (ed) Brain Microdissection Techniques. Wiley, New York, pp 1-186

21. Palkovits M 1977 Isolated removal of hypothalamic or other brain nuclei of the rat. Brain Res 134:449-450

22. Lowry DH, Rosenbrough NJ, Farr AL, Randall RJ 1951 Protein measurement with the folin phenol reagent. J Biol Chem 193:265-275

23. Arregui A, Barer GR, Emson PC 1981 Neurochemical study in hypoxia substance $P$, methionine-enkephalin, GABA, angiotension converting enzyme. Life Sci 28:2925-2929

24. Long WA, Lawson EE 1984 Neurotransmitters and the biphasic respiratory response to hypoxia. J Appl Physiol 57:213-222

25. Baker JL, Neale JH, Smith TG Jr, MacDonald RL 1978 Opiate peptide modulation of amino acid responses suggests novel form of neuronal communication. Science 199:1451-1453

26. Schwartz JC, Roques BP 1980 Opiod peptides as intracellular messengers Biomedicine 32:169-175

27. Klein RL, Wilson SP, Ozielak OJ, Yang WH, Viveros OH 1982 Opioid peptides and noradrenaline co-exist in large dense-cored vescicles from sympathetic nerve. Neuroscience 7:2255-2261

28. Kosterlitz HW 1984 Opioid peptides and interneuronal coexistence of transmitters. In: Chan-Palay V, Palay S (eds) Co-Existence of Neuroactive Substances in Neurons. Wiley and Sons, New York, pp 325-339

29. McNamara MC, Gingras-Leatherman JL, Lawson EE 1986 Effect of hypoxia on brainstem concentration of biogenic amines in postnatal rabbits. Dev Brain Res 25:253-258

30. Zamir N, Weber E, Palkovits M, Brownstein M 1984 Differential processing of prodynorphin and proenkephalin in specific regions of the rat brain. Proc Natl Acad Sci USA 81:6886-6889 